ment for patients with carcinoma of the breast and prostate who suffer extreme pain from metastases in bone. But relief of pain can now be assured in the majority of cases by bilateral adrenalectomy. Regression of the primary tumour occurs much less frequently than that of the metastases.

Bilateral adrenalectomy is a practical proposition and no undue hardship is imposed upon the adrenalectomised patient.

\section{BIBLIOGRAPHY}

BEATSON, G. T. (1896), Lancet, ii, 104 and 162. BOYD S. (1900), Brit. med. F., ii, II6I.

BURROWS, H., and HORNING, E. S. (1952), 'Oestrogens and Neoplasia', Blackwell, London.

DARGENT, M. (1949), Brit. med. $\%$., ii, 54 .

FARROW, J. H., and WOODARD, 'H. Q. (1942), f. Amer. Med. Ass., 118, 339.

L. (1949), Brit. F. Cancer, 3, 240 and 345

GALTON, D. A. G. (1950), Brit. F. Cancer, 4, 20.

HERRELL, W. E. (1937), Amer. $\Im$. Cancer, 39, 659.

HUGGINS, C. C., and HODGES, C. V. (194I), Cancer Res., 1, 293. HUGGINS, C. C., and SCOTT, W. W. (1945), Ann. Surg., 122, 1031. LATHROP, A. E. C., and LOEB, L. (1916), 手. Cancer Res., r, 1 . STOLL, 3. ^... nd ELLIS, F. (1953), Brit.Med.尹., 11, 796.

\title{
THROMBOSIS OF THE INTERNAL CAROTID ARTERY
}

By Simon Behrman, B.Sc.(Hon.)Lond., M.R.C.P.Lond.

Physician, Moorfields, Westminster and Central Eye Hospital; Consulting Neurologist S.E. and N.E. Metropolitan Regional Hospital Boards

Numerous are the instances in the annals of medicine of discoveries made and subsequently forgotten, but this cycle seems to have recurred several times before angiography of the carotid artery revealed anew the frequency and the complications of occlusion of the internal carotid artery. The reasons for this recurring oblivion were twofold:

I. Examination of carotids in the upper part of the neck and carotid canals is not usually performed in routine autopsy.

2. Ramsay Hunt in I9I4 gave the other reason for the neglect of this subject as follows: "The assumption that the circle of Willis is sufficient to carry the blood into an obstructed vascular area when such obstruction is situated below the level of the anterior and posterior communicating arteries.' 1

This assumption was not only based on anatomical grounds but also on the experience of the effects of ligaturing these arteries. This operation was frequently performed during the rgth century for a variety of 'nervous disorders' such as epilepsy and trigeminal neuralgia, as is testified by the publication of four large series of cases collected during the second half of the century and quoted by Ramsay Hunt. In only 16 per cent. of some 1,200 cases comprising a variety of conditions did cerebrovascular accidents superveneand this before the days of asepsis!

The present revival of interest in the subject of carotid thrombosis began after cerebral angio- graphy came into wide use, and confirmed Ramsay Hunt's contention that occlusion of carotid arteries was not uncommon.

\section{Pathology}

Frequency. On combining the three large published series of unselected post-mortem examinations, which included a routine inspection of the carotid arteries in their entirety, the incidence of macroscopically visible thrombosis and embolism of this artery can be said to be approximately $\mathbf{1 . 6}$ per cent. ${ }^{2,3,4}$ The incidence will to some extent vary in accordance with the average age of the autopsy material.

The following classification of the various conditions causing occlusion of the carotid artery either by thrombosis or embolism has been suggested by Hultquist:

I. Trauma.

2. Morbid processes affecting the tissues in the immediate relation of the carotid arteries.

3. Cardiovascular diseases.

\section{Trauma}

Non-penetrating injuries to the neck may occasionally be followed within 6 to 48 hours by rapid onset of hemiplegia due to spreading thrombosis of the internal carotid artery. This was described by Northcroft and Morgan, and more recently the subject was reviewed by Schneider and Lemmen. 5,6 Cases of this nature simulate extradural and subdural haematomas, as is illus- 
trated by the following case reported by Northcroft and Morgan.

Case 1. Male, aet. 31. A piece of loose rope hanging from the side of a passing lorry wound itself round the patient's neck, threw him to the ground and then unwound itself without dragging him along. He picked himself up and though feeling faint was able to proceed on foot to the Unit Medical Officer, who noticed bruising of the left side of the neck. About 24 hours after the accident the patient had a right-sided epileptic fit followed by right flaccid paralysis and coma. He died 48 hours after the accident. Autopsy suggested that the original injury resulted in extravasation of blood into the media of the internal carotid artery extensive enough to cause occlusion of the vessel. Intraluminal thrombosis was found above and below the level of the vessel injury, the upper thrombus extending upwards into the middle cerebral vessels.

\section{Morbid Processes Affecting Tissues in Immediate Relation of the Carotid Arteries}

(a) Inflammation. Otitis media with spread of infection to bony carotid canal. Meningitis with thrombosis of cavernous sinus. Peritonsilar abscess. Aseptic cavernous sinus thrombosis followed later by convulsions and contralateral hemiplegia. ${ }^{7}$

(b) Neoplasms. Sphenoidal ridge meningioma. Malignant tumours at the base of the skull.

\section{Cardiovascular Diseases}

(a) Diseases of the carotid artery causing occlusion. The incidence of atherosclerosis of the internal carotid is high, as has been shown by several publications involving the examination of this artery in series of unselected autopsies. ${ }^{8,9}$ The localization of atherosclerosis is probably related to the magnitude of the circumferential stretching force to which different portions of the vessel wall are subject. ${ }^{10}$ Broadly speaking this force can be expressed by Laplace's Law, according to which it is proportional to intravascular pressure and the radius of the vessel. Atherosclerosis is minimal where the pressures within and outside the artery are almost equal. This obtains in portions of the artery well supported by non-yielding surrounding structures, e.g. the portion of the carotid within the bony canal. Experimentally these conditions have been simulated by applying silver cuffs about the circumference of short segments of arteries in rabbits. Willens noted that the enclosed artery was not affected by atherosclerosis when animals were fed with cholesterol.11

According to Laplace's Law the circumferential tension is proportional to the radius of the vessel. Two segments of internal carotid show antrum like dilatations, viz., at the level of the carotid sinus and immediately after the emergence from the cavernous sinus. Atheromatous changes are most pronounced in these situations where this localized increase in the radii occurs.

Thromboangiitis obliterans and giant cell arteritis are two other vascular diseases liable to cause thrombosis of the internal carotid artery. ${ }^{12}$

(b) Embolism. The lumen of the carotid can be occluded by emboli originating in the heart, e.g. bacterial endocarditis and coronary infarction. ${ }^{13}$

\section{Effect of Occlusion of the Internal Carotid Artery}

Dye injected into the carotid artery is normally distributed only to the homolateral hemisphere, but should the contralateral common carotid be compressed during the angiographic procedure, the dye will be seen in the vascular systems of both hemispheres in equal amounts. This angiographic evidence serves to confirm the well known fact that occlusion of one carotid artery is immediately compensated and normally does not evoke any abnormal symptoms. Even when the E.E.G. is used as an index of cerebral disturbance, no abnormalities can usually be detected on unilateral carotid compression, provided stimulation of the carotid sinus is avoided. Normal cerebral circulation under these conditions depends on the integrity of the circle of Willis and the adequacy of the communicating vessels and of the remaining main arteries of the brain. Provided these conditions obtain, spontaneous occlusion of one internal carotid artery is also not fraught with any abnormal symptoms. For compensation of such occlusion, it is essential that a sufficient amount of blood per unit of time should reach the portion of the cerebral hemisphere normally supplied by this artery. This volume of blood has to be conveyed by the communicating arteries and anastomosing vessels. Since the volume of blood circulating through a vessel per unit of time is, broadly speaking, governed by·Poiseuille's Law, two factors determine whether such compensation can be effected:

I. Diameter of the vessel. The volume of flow per unit of time is proportional to the fourth power of the diameter and therefore even slight narrowing of the concerned vessels by disease will considerably reduce the flow.

2. Since the flow is directly proportional to the pressure, this is also a factor which must be taken into consideration. If under given conditions of pressure the communicating and anastomosing vessels are, either through disease or maldevelopment, insufficient to compensate, a state of circulatory insufficiency will result and, depending on its severity and duration, this will give rise to 
various signs and symptoms referable to the ischaemic region of the hemisphere. Some of these disturbances may be caused by cerebral infarction and may thus be permanent. In 60 of IOO cases of fatal cerebral infarction Hicks and Warren were unable to find evidence of mechanical occlusion of cerebral vessels. ${ }^{14}$ Should the remaining main vessels be narrowed or occluded by disease, then following occlusion of one internal carotid artery, cerebral insufficiency may affect both hemispheres. Recent studies of the effect of ligature of the internal carotid have provided some information to indicate that the subject of circulatory insufficiency is far more complex than a simple consideration of Poiseuille's Law would suggest. Thus following ligature of the carotid not only does the fall in pressure vary from individual to individual, as was only to be expected, but results are subject to considerable variations in the same individual without any changes in the general blood pressure to account for it. One of Dandy's patients, for instance, tolerated complete closure of the internal carotid in the neck within one week of the first operation, when such closure evoked neurological signs of cerebral ischaemia. ${ }^{15}$ Measurements of pressure within the carotid distal to ligature may show striking differences in the same individual, as was shown by Bakay and Sweet. ${ }^{16}$ l'ressure fell to 23 per cent. of that prior to ligature. When the ligature was re-applied six days later it dropped only to 48 per cent. of the original pressure. Serial pressure readings carried on for as long as 60 minutes in other cases revealed rise and also fall in pressures without corresponding changes in blood pressure. Some of these pressure changes are no doubt due to the effects of arterial spasm set up by the ligature. Clinical evidence of cerebral circulatory insufficiency following carotid ligation may appear abruptly or insidiously even after intervals as long as five to six days, and such symptoms can be abolished by the removal of the ligature thus proving the patency of the cerebral vessels in such cases.

\section{Break in the Circle of Willis}

Anatomical studies have revealed that the anterior communicating artery is deficient in 10 per cent. and one of the post-communicating arteries in 23 per cent. ${ }^{17}$ Extension of thrombi from the internal carotid artery, as also emboli arising from such thrombi, may cause a break in the circle of Willis.

\section{Consequences of Thrombosis of Carotid Artery}

As has already been shown, cerebral circulation is normally unaffected by occlusion of one of the carotid arteries. However, in some cases cerebral circulation may be critically dependent upon the integrity of the carotids, and apoplexy may follow occlusion of one carotid; in others complications may arise after an interval. These may be caused by any of the following three processes, either singly or in combination:

I. Cerebral circulatory insufficiency (already reviewed).

2. Spreading thrombosis so that thrombus extends into the circle of Willis or cerebral arteries. Case I illustrates this.

3. Emboli which may become detached from the main thrombus of the internal carotid artery. The following case illustrates a massive embolism of this nature:

Case 2. Atheroma of left internal carotid artery-thrombosis-detached portion of thrombus causing embolism of middle cerebral arterythrombophlebitis of veins of legs-pulmonary embolism.

Female, aet. 35. The patient had been in excellent health until four weeks before admission. While having a meal she had twitching of the right side of the face and developed uselessness of the right arm for a short time. She remained well until the day of admission when she suddenly lost

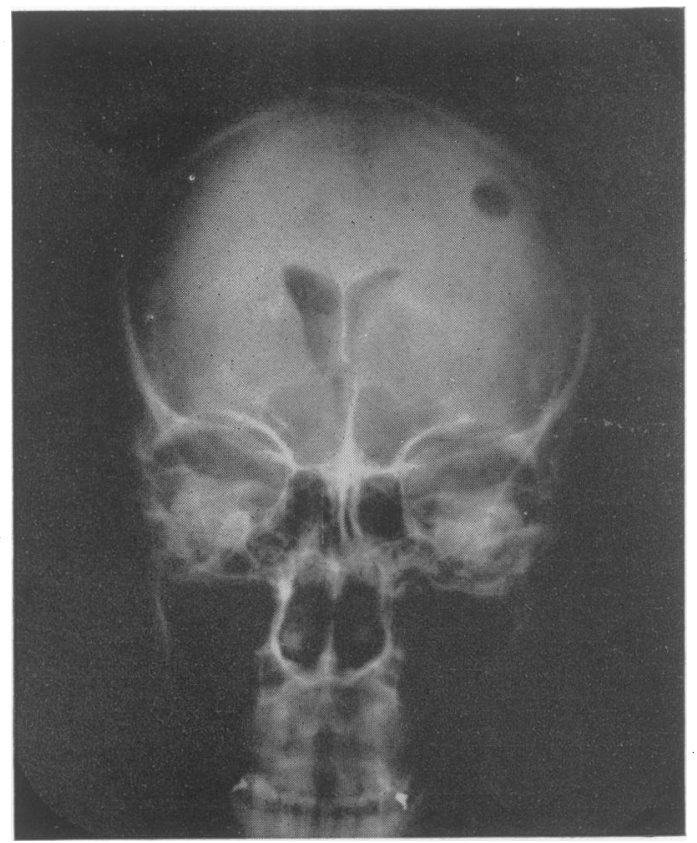

FIG. I.- Ventriculogram showing considerable degree of cerebral oedema in a proved case of thrombosis of left internal carotid artery (Mr. Ian McCaul's case). 
her speech, sat down, fell back and had a generalized convulsion. Following this she was found to be aphasic and paralyzed down the right side of her body. She died suddenly one week after admission, following a brief period of breathlessness and cyanosis; death was due to extensive pulmonary embolism.

Carotid artery showed organizing thrombus attached to the wall which, at the level of bifurcation, was the site of considerable atheromatous deposits beneath the intima and had patchy areas of intimal hyperplasia. The thrombus was about $7 \mathrm{~cm}$. long with its centre approximately at the level of the bifurcation. A recent embolus in the left middle cerebral artery, which was otherwise free from disease, was responsible for extensive infarction of the left parietal and temporal lobes, together with the basal ganglia. The gross swelling of the brain substance had well-nigh closed the ventricular space.

Authors have differed in the relative importance they have attached to these three factors. Cerebral circulatory insufficiency has been stressed by Corday et al., spreading thrombosis by Hultquist and embolism by Chiari. ${ }^{18}$ In any given case the assessment of the part played by these factors cannot be made on clinical grounds alone since, following cerebral embolism and cerebral thrombosis, the paralytic phenomena may occasionally be only transient and cerebral circulatory insufficiency may cause irreversible cerebral damage. As a broad generalization, however, it can probably be stated that cerebral embolism and cerebral thrombosis give rise to enduring disturbances and that stereotyped recurrent paralytic episodes followed by recovery are most frequently due to cerebral circulatory insufficiency. The following clinical types can be recognized:

\section{Clinical Types}

I. Massive apoplectiform hemiplegia, either due to thrombosis or embolism of the main cerebral vessels or occlusion of the carotid in the presence of a break in the circle of Willis.

2. Recurrent transient paralytic phenomena with recovery-presumably due to cerebral circulatory insufficiency.

3. Various paralytic phenomena with only partial recovery-multiple embolic phenomena.

4. Progressive hemiparesis with or without fits simulating tumour.

\section{Clinical Features of Carotid Occlusion}

As will be appreciated from the survey of the complex nature of the factors responsible for the overt manifestations of carotid thrombosis, the range of symptoms and their degree of intensity must, of necessity, be wide. Cerebral emboli may be discreet or massive, cerebral circulatory insufficiency, according to circumstances, slight or grave and the consequent symptomatology exceedingly variable. The different clinical types have already been outlined and it only remains to mention briefly some of the symptoms most frequently seen with each type.

Type I. Hemiplegia with or without coma; often preceded by convulsions, predominantly unilateral. In addition to hemiplegia there may be unilateral sensory loss and hemianopia.

Type 2. Symptoms are of brief duration and tend to recur as evanescent episodes of stereotyped nature. The commonest transient symptoms are: Monocular amaurosis, dysphasia, attacks of 'dizziness,' monoplegia and sensory disturbances in limbs.

Type 3. Every type of cerebral paralytic phenomena, either singly or in combination, can be expected to occur and have been described in reported cases, a review of which reveals in addition to such common forms of paresis as motor or sensory monoplegia or hemiplegia, dysphasia, dysgraphia, dyslexia and dyspraxia and also a great variety of less common symptoms resulting from disturbance of cerebral function.

Type 4. This type is of particular importance because the clinical picture mimics that of cerebral neoplasm very closely. Progressive dementia can be a feature in these cases.

In addition to the various cerebral paralytic and epileptic phenomena mentioned and the visual disturbances about to be described, headache is the only remaining important symptom. The incidence, severity and character would appear from the published and personal cases to be too variable to permit of a formulation of any definite pronouncement regarding pathogenesis. These headaches are usually maximal on the affected side and may well be due to dilatation and increased pulsation of pial and cerebral vessels caused by cerebral circulatory insufficiency. Dilatation of these vessels in animals has been demonstrated in experimental anoxaemia induced by various methods and also when blood pressure has been lowered to a critical level. ${ }^{19,20}$ Since headache of high intensity is a constant feature of active giant cell arteritis it constitutes one of the main symptoms of carotid thrombosis caused by this vascular disorder.

\section{Disturbances of Vision}

A discussion of some of the common ophthalmological manifestations of carotid thrombosis must be prefaced by stressing the following anatomical and physiological facts:

I. Within the eyeball the pressure of the central retinal artery is opposed by the intraocular pres- 
sure of about $20 \mathrm{~mm} . \mathrm{Hg}$ and therefore the effective intravascular pressure is reduced by this amount. A variety of 'blackouts' can be shown to be resulting from this physiological arrangement. ${ }^{21}$

2. There is free anastomosis between the ophthalmic artery and branches of the external carotid artery so that occlusion of the ophthalmic artery does not as a rule lead to interruption of circulation through the central retinal artery. ${ }^{22}$

3. Sudden permanent unilateral amaurosis occurring in the course of carotid thrombosis usually takes place without any demonstrable lesion in the course of the ophthalmic artery. ${ }^{23,}{ }^{24}$

Amaurosis in these cases can only be explained on the basis of embolism or circulatory insufficiency and these two possible factors will now be considered in greater detail. We have seen that there is ample pathological evidence indicating that cerebral embolism is often a feature in carotid thrombosis and there is, therefore, reason to believe that such emboli may also reach the retinal vessels. Such embolism is most likely to give rise to enduring amaurosis owing to irreversible retinal damage. In cases in which through maldevelopment or disease there is a break in the circle of Willis, the fall of pressure in the internal carotid following thrombosis may be considerable. After ligature of the internal carotid, as Strobos and Mount have shown, the pressure gradient between the internal carotid and ipsilateral small cortical vessels is maintained. ${ }^{25}$ Assuming that this relationship also obtains between the internal carotid and central retinal artery, then a 60 per cent. fall of pressure will bring the pressure within the first branches of the central retinal artery from approximately $70 \mathrm{~mm}$. down to $28 \mathrm{~mm}$. Normal intraocular pressure will oppose this pressure and impede retinal circulation, which may become insufficient to maintain retinal function with resulting amblyopia. A drop of pressure in the internal carotid of 55 to 65 per cent. after ligation is compatible with normal cerebral function, as has been shown by Strobos and Mount and also Sweet and Bennett. ${ }^{26}$ Thus it can be supposed that a fall of carotid pressure of certain ' critical' value will give rise to amblyopia or amaurosis without symptoms indicative of disturbance of cerebral function. The fall of intraocular pressure which may result from this fall of carotid pressure may be one of the means whereby a dynamic adjustment can be effected. In those cases of internal carotid thrombosis in which the posterior communicating artery contributes little towards the ipsilateral cerebral circulation, compression of the unaffected carotid may result in a considerable fall of the carotid pressure. ${ }^{26} \mathrm{~A}$ fall of 'critical' magnitude under these circum- stances would explain the observation made by Denny-Brown on one of his patients. ${ }^{27}$ On one of the patients with thrombosis of the left internal carotid artery, 'manual compression of the right carotid caused immediate blanching of the vessels of the left fundus and marked pulsation of the right fundus.' Under these conditions intraocular pressure presumably exceeded systolic pressure of the left and diastolic pressure of the right central retinal arteries.

\section{Absence of Carotid Pulsation}

Considerable diagnostic importance was attached by Ramsay Hunt to loss of pulsation in the internal carotid artery. However this is on the whole an infrequent finding, partly because the occlusion may be distal to the cervical portion of the artery and partly because the thrust of each pulse wave may be transmitted along the artery for some distance beyond the embolus or thrombus. However Dunning claims that this examination is best performed by feeling for pulsation on each side of the pharynx. ${ }^{28}$

\section{Paediactric Aspect}

Considering the infrequency of cerebrovascular accidents in childhood the number of children among the published cases of internal carotid thrombosis is surprisingly high. ${ }^{29,}, 30,31,32$

Case 3. Boy, aged 7. Generalized erythematous rash for three days associated with malaise. Two weeks later severe headache and puffiness of eyes, followed on the next day by swelling of face and the passing of deep red urine. One month later developed severe headache. On the following day when he awoke he was found to have right hemiplegia. His speech was slowed and he noticed loss of left vision. During the following week he recovered function of the right limbs. Peeling of hands and feet was noticed at this time. On examination he showed left optic atrophy and right hemiparesis. Pulsation of left carotid artery could be hardly appreciated, whereas pulsation of right carotid was within normal limits. Blood pressure, 90/60. Examination of urine, C.S.F. and radiograms of the skull revealed no abnormality.

\section{Radiological Abnormalities}

I. Angiography. Failure to visualize the contrast medium in the vessel does not necessarily mean it is thrombosed. Spasm provoked by the mechanical stimulation by the needle may. produce a similar effect and the following criteria are of help in the differentiation between thrombosis and spasm of the internal carotid artery.

(a) Filling of the middle cerebral group of vessels and perhaps of the carotid syphon about 
four seconds after the injections (i.e. in the phlebogram).

(b) Repeated angiograms reveal partial filling or absence of filling of the internal carotid.

(c) Contralateral angiogram visualizes cerebral vessels of both sides.

(d) Absence of filling of the syphon despite compression of contralateral carotid, a procedure not without danger. ${ }^{33}$

Conical narrowing of the stream of contrast medium before it stops, as also narrowing of the vessel without interruption of the stream, are features which suggest thrombosis. Very occasionally films taken subsequent to the arteriography may reveal accumulation of some contrast medium in the area of infarction. ${ }^{34}$

2. Pneumography. Ventriculography following carotid thrombosis may reveal in the early stage a considerable degree of ipsilateral cerebral oedema (Case 2, see Fig. I) or ipsilateral cerebral atrophy at a late stage.

\section{Electroencephalography}

Various E.E.G. abnormalities have been noted in association with carotid thrombosis. However, slow delta waves localized to the ipsilateral frontotemporal region is the commonest type of abnormality. In three out of four cases of carotid thrombosis Skillicorn and Aird have observed that compression of the non-affected common carotid artery resulted in the appearance of high voltage slow irregular waves, two to five per second frequency, usually in both hemispheres. ${ }^{35}$

\section{Treatment}

As has been indicated, the serious consequences of carotid thrombosis are due to cerebral circulatory insufficiency and cerebral embolism. Little can be done to overcome cerebral circulatory insufficiency, but much can be done by various medical procedures to aggravate it and these should be avoided if possible. Ventriculography by raising intracranial pressure and angiography by setting up spasm in the carotid tree may have unfavourable effects. There are many instances in the literature describing various cerebrovascular accidents immediately following these investigations which have been performed because of the suspected possibility of intracranial neoplasm. The differential diagnosis on clinical grounds alone between carotid thrombosis and intracranial neoplasm may in certain cases be impossible and these radiological aids to diagnosis have to be enlisted. Cerebral embolism constitutes a serious hazard and on theoretical grounds ligature distal to the site of thrombosis can be justified. It is, however, not a practical measure in the majority of cases. It has been argued that the thrombosed segment of the artery sets up irritation and thus provokes vasospasm peripheral to the point of occlusion and it has, therefore, been suggested that resection or denervation of the affected segment may lead to relaxation of the distal arterial tree and this may help to overcome cerebral circulatory insufficiency. ${ }^{36}$ The available data are too meagre to permit of any definite conclusions as to the value of this treatment.

\section{Summary}

I. Four main clinical types of internal carotid thrombosis are described.

2. These various clinical types are the result of the interplay of the following three main causative factors:

(a) Cerebral circulatory insufficiency resulting from a break in the circle of Willis, either congenital or acquired.

(b) Spreading thrombosis so that the thrombus extends into the circle of Willis or cerebral arteries.

(c) Embolism originating from the main thrombus of the internal carotid artery.

3. The mechanism for monocular amblyopia in the absence of any simultaneous symptoms indicative of disturbance of cerebral function is discussed. It is suggested that in the presence of a lowered carotid pressure, intraocular pressure is the main factor in the production of this syndrome. In some cases permanent monocular amaurosis is due to embolism.

4. Analysis of the published case histories of internal carotid thrombosis reveals that the condition is not uncommon in children, and a further case is reported.

\section{Acknowledgment}

I wish to thank Sir Russell Brain for permission to publish details of Case 3 .

\section{REFERENCES}

I. HUNT, J. RAMSAY (1914), Amer. F. med. Sci., 147, 704.

2. CHIARIS, H. (1905), Verhandl. d. deutsch. path. Gesellsch., 9, 326.

3. KRAYENBUHL, H., and WEBER, G. (1944), Helv. med. Acta., 11, 289.

4. HULTQUIST, G. T. (I942), 'Ueber Thrombose u. Embolie d. Arteria Carotis u. hierbei vorkommende Gehirnstörungen,' Jena, Gustav Fischer.

5. NORTHCROFT, G. B., and MORGAN, A. D. (1944-5), Brit. F. Surg., 32, 105.

6. SCHNEIDER, R. C., and LEMMEN, L. J. (I952), $\boldsymbol{f}$. Neurosurg., 9, 495.

7. WALSH, F. B., and SMITH (1952), Ibid., 9, 517.

8. KEELE, C. A. (1933), Quart. F. Med., 2, 213.

9. HASSELBACH, H. (1931), Beitz. z. path. Anat. u. z. allg. path., 86, 369.

I0. WILliS, G. C. (1954), F. Canad. med. Ass., 70, I.

I I. WILLENS, S. L. (1942), Amer. F. Path., 18, 63.

12. GILMOUR (I94I), f. Path. Bact., 53, 263.

13. WINKELMAN and ECKEL (1930), Arch. Neurol. Psych., 23, II6r.

14. HICKS, S. P., and WARREN, S. (195I), Arch. Path., 52, 403. 15. DANDY (1942), Arch. Surg., 45, 521.

16. BAKAY, L., and SWEET, W. H. (1953), F. Neurosurg., 10, 353.

References continued on page 592 
huge posterior penetrating duodenal ulcer involving the region of the bile ducts was found. The prepyloric region was opened and it was found that clear bile and no fresh blood came back from the duodenum, and so presumably the bleeding had ceased. After removing the antral mucosa, the sero-muscularis of the antrum was closed, and a partial gastrectomy performed. Following this he improved day by day, but on the eighth day, massive melaena recurred. I felt that the ulcer could hardly be active after this space of time and so we treated him conservatively thereafter. He died of repeated bleeding about a week later.

At autopsy, the ulcer indeed was found to have practically healed (Fig. 28), the small unhealed part being entirely occupied by a ruptured aneurysm, the rupture of which had no doubt led to the repeated bleeding.

Another conservative method for bleeding posterior duodenal ulcer favoured at times and which we used for a period, was duodenotomy, arrest of bleeding by suture together of the ulcer edgesfollowed by gastro-jejunostomy. I used this on eight occasions, but in two patients, the bleeding recurred and one died of it. I do not use this method now.

After recounting my experiences with the various régimes in the treatment of ulcer haemorrhage, you will see that I am inclined to favour surgery. That does not mean that I am advocating surgery universally. There is a considerable variation in the type of case treated in different places, and our 3 preponderance of elderly gastric ulcer cases makes $\stackrel{\square}{\square}$ surgery particularly suitable. It is not without $\stackrel{.}{.}$ significance that we have such a volume of work $\overrightarrow{\vec{F}}$ that we are able to keep in practice for these operations.

I have gone over a very wide field and so have, perhaps, only been able to give an over-all im- $\overline{\mathbb{}}$ pression of our present practices in dealing with peptic ulcer and its complications.

\section{BIBLIOGRAPHY}

BRAIN, R.H. F., and STAMMERS, F. A. R. (195 I), Lancet, 1 , 1137. CAPPER, W. M., and BUTLER, T. J. (1951), Brit. med. F., ii, 265. FINSTERER, H. (1947), Wien, med. Wschr., 97, 3.

GILMOUR, J. (1953), Lancet, i, 870.

GORDON-TAYLOR, G. (1945), Trans. med. Soc. Lond., 64, 197. LOWDON, A. G. R. (1952), Lancet, i, 1270.

MCCREATH, N. D. (1953), Personal communications.

MIMPRISS, T. W., and BURT, St. J. M. C. (1948), Brit. med. 7. ii, 1095 .

MORONEY, J. (1951), Lancet, i, 993.

POLLARD H BOLT R J, RANSOM, H. K., and OREBAUGH, J. E. (1952), $\dot{F}$. Amer. med. Ass., 150, 1476.

QUINN, W. F., and GIFFORD, J. H. (1950), California Med., $72,18$.

SHANKS, S. C. (1952), Trans. med. Soc. Lond., 67, 136. SWYNNERTON, B. F., and TANNER, N. C. (1953), Brit. med. f., ii, 841 .

TANNER, N. C. (1949), Ibid., i, I 10.

TANNER, N. C. (1951), Langenbeck's Arch. u. Deutsch Z. Chir 267, 369 .

TANNER, N. C. (1951), Edin. med. $\mathcal{F} ., 58,288$.

TANNER, N. C. (1952), Ann. Roy. Coll. Surg., 10, 45.

TAYLOR, H. (195I), Lancet, i, 7.

WANGENSTEEN, O. H. (1949), Surg. Gynec. and Obstet., 88, 56gt

Refercnces continued from page 576-Simo: Behrman, B.Sc.(Hon.)Lond., M.R.CP.,Lond.

17. FETTERMAN, G. H., and MORAN, J. J. (1941), Arch. Páth., 32, 25 I.

18. CORDAY, E., ROTHENBERG, S. F., and PUTNAM, TRACY' J. (1953), Arch. Neurol. Psych., 69, 551 .

19. WOLF., H. G., and LENNOX, W. G. (1930), Ibid., 23, $1097 \cdot$

20. WOLF, H. G. (1936), Physiol. Rev., 16, 545.

21. BEHRMAN, SIMON (1951), Arch. Ophthal., 45, 458.

22. WALSH, F. B., and KING, A. B. (1942), Ibid., 27, I.

23. ASKENAZY (1952), Folia Psych., 55, 55.

24. Personal Case.

25. STROBOS, R. R. J., and MOUNT, L. A. (1953), Arch. Neurol. Psych., 69, 118.

26. SWEET, W. H., and BENNETT, H. S. (1948), f. Neurosurg., 5 , 178.
27. DENNY-BROWN, D. E. (1954), M. Clin. Nth Amer., 35, 1457.

28. DUNNING, H. S. (1953), Arch. Neurol. Psych., 70, 53 I.

29. HYLAND, H. H. (Case 3) (1933), Ibid., 30, 342.

30. KING, A. B., and LANGWORTHY, O. R. (Case I), (1941), Ibid., 46, 835 .

31. DUTAILLIS, P. (1949), Rev. Neur., 81, 997.

32. SHAPIRO, R. (Case I) (1952), Radiol., 58, 94.

33. LE BEAU, M. J. (1949), Rev. Neur., 81, 1029.

34. ABBOTT, K., quoted by HAMBY, W. B. (1052), 'Intracranial Aneurysms,' Thomas, Springfield, U.S.A.

35. SKILLICORN, S. A., and AIRD, R. B. (1954), Arch. Neurol. Psych., 71, 367.

36. CHAO W. H KWAN S. T. LYMAN, R. S., and LOUCKS, H. H. (1938), Arch. Surg., 37, 100. 